\title{
Cytochrome C Oxidase Assembly Protein COX11, Mitochondrial
}

National Cancer Institute

\section{Source}

National Cancer Institute. Cytochrome C Oxidase Assembly Protein COX11,

Mitochondrial. NCI Thesaurus. Code C90144.

Cytochrome c oxidase assembly protein COX11, mitochondrial (276 aa, $231 \mathrm{kDa}$ ) is encoded by the human COX11 gene. This protein is involved in the assembly of cytochrome c oxidase. 